Article

\title{
Azelaic Acid Esters as Pluripotent Immunomodulatory Molecules: Nutritional Supplements or Drugs
}

\author{
Elzbieta Izbicka ${ }^{*}+\mathbb{D}$ and Robert T. Streeper ${ }^{\dagger}$ \\ New Frontier Labs LLC, San Antonio, TX 78209, USA; rstreeper.g4@gmail.com \\ * Correspondence: eizbicka.g4@gmail.com; Tel.: +1-210-725-6868 \\ + These authors contributed equally to this work.
}

check for updates

Citation: Izbicka, E.; Streeper, R.T. Azelaic Acid Esters as Pluripotent Immunomodulatory Molecules: Nutritional Supplements or Drugs. Nutraceuticals 2021, 1, 42-53. https:// doi.org/10.3390/nutraceuticals1010006

Academic Editors: Anna Iwaniak and Luisa Tesoriere

Received: 22 October 2021

Accepted: 13 December 2021

Published: 17 December 2021

Publisher's Note: MDPI stays neutral with regard to jurisdictional claims in published maps and institutional affiliations.

Copyright: (c) 2021 by the authors. Licensee MDPI, Basel, Switzerland. This article is an open access article distributed under the terms and conditions of the Creative Commons Attribution (CC BY) license (https:/ / creativecommons.org/licenses/by/ $4.0 /)$.
Abstract: Azelaic acid and its esters, the azelates, occur naturally in organisms ranging from plants to humans. We have shown that diethyl azelate (DEA) exhibits a broad range of immunomodulatory activities in vitro and in vivo, and mitigates insulin resistance. To further investigate the therapeutic utility of DEA, we evaluated its mutagenicity in Salmonella typhimurium strains, examined metabolism of DEA in rat, dog, monkey and human primary hepatocytes and in human saliva, determined pharmacokinetics of DEA after an oral dose in rats, and queried its physicochemical properties for drug-like characteristics. DEA was not mutagenic in bacterial strains \pm rat liver metabolic activation system S-9. It was chemically unstable in hepatocyte culture medium with a half-life of $<1 \mathrm{~h}$ and was depleted by the hepatocytes in $<5 \mathrm{~min}$, suggesting rapid hepatic metabolism. DEA was also quickly degraded by human saliva in vitro. After an oral administration of DEA to rats, the di- and monoester were undetectable in plasma while the levels of azelaic acid increased over time, reached maximum at $<2 \mathrm{~h}$, and declined rapidly thereafter. The observed pharmacological properties of DEA suggest that it has value both as a drug or a nutritional supplement.

Keywords: azelaic acid ester; diethyl azelate; immunomodulation; nutritional supplement; drug metabolism

\section{Introduction}

Azelaic acid (AZA is a nine-carbon (C9) dicarboxylic acid occurring naturally in plants, animals, and humans. AZA is endogenously formed from longer chain dicarboxylic acids and omega-oxidation of nonanoic acid. Other precursors of AZA are dietary fatty acids, especially oleic acid, a C18 monounsaturated omega-9 fatty acid present in olive oil. Oleic acid is also endogenously produced in the human body [1].

AZA and the azelates act as immunomodulators in organisms ranging from plants to humans. In plants, AZA is a key part of an innate immune response to pathogen infection and serves as a signal that induces the mobilization of salicylic acid, a plant hormone that activates multilevel defensive responses [2,3]. AZA modulates the innate immune responses in human skin [4,5]. The immunomodulatory role of the azelates, and especially diethyl azelate (DEA), has been discovered only recently [6,7]. These findings suggest highly conserved functions of AZA and azelates in multicellular organisms.

AZA and the azelates have been part of the human diet for millennia due to their abundance in olives, grains, and soybeans. Azelate content in foods is increased by fermentation due to bacterial metabolism of acyl glycerol fatty acids and esterification of the resulting medium chain fatty acids [8]. Fermentation of olives by Lactobacilli to render them edible [9] converts some of the oleic acid into AZA and azelates [10]. Fermentation of rice also results in the formation of fatty acid ethyl esters [11]. AZA and its esters are present in douchi, a fermented black bean product [12], and in alcoholic beverages made from grains and soybeans [13-15].

Azelates are currently utilized as lubricants, plasticizers, and flavor additives. AZA has been used as a topical drug for several decades. Select classical and more recent studies 
on AZA describe a breadth of its biomedical applications [16-20]. However, the azelates have been little explored as drugs. We have identified the azelates as representatives of a new class of drugs and discovered a number of potential applications of DEA and other azelates in treating diverse human pathologies $[6,7,21]$.

In our past studies, we have found that DEA is not mutagenic using in silico and in vitro assays, and it is not cytotoxic in various types of primary normal human cells [6]. Importantly, we have found that oral DEA has displayed an inverse U-shape dose response effect with an optimum around $1 \mathrm{mg} / \mathrm{kg}$ [21-23]. Such a dose was used in daily oral applications of DEA over three weeks in the clinical study in overweight adult males, which demonstrated significant effects of the orally administered DEA on biomarkers of insulin resistance such as blood plasma glucose, insulin, and lipids [24]. Similar DEA oral doses around $1 \mathrm{mg} / \mathrm{kg}$ are intended in the future efforts of the development of DEA as a drug and/or a nutritional supplement.

The goal of the present work was to expound upon the suitability of DEA as a food supplement or a drug. This manuscript describes a number of preclinical tests that are typically required for the registration of a drug candidate in the US and worldwide. Our earlier work referenced above informed the doses of DEA used in the preclinical tests.

We have shown that DEA lacks mutagenicity, is rapidly metabolized in mammals, and that it possesses a number of useful pharmacological properties. These findings support development of DEA as a nutritional supplement and/or a novel therapeutic.

\section{Materials and Methods}

\subsection{Chemical Synthesis}

DEA (CAS 624-17-9) was synthesized by esterification of AZA with ethanol and purified to $99 \%$ purity as determined by gas chromatography-mass spectrometry (GC-MS) [24].

\subsection{Bacterial Reverse Mutation Assay}

The studies were conducted by Covance Laboratories Inc. (Madison, WI, USA) in accordance with the company standard operating procedures. The assay in Salmonella typhimurium strains TA98, TA100, TA1535, TA1537, and TA102 in the absence or presence of rat liver metabolizing system (S-9) followed an established method [25]. The mutagenic compounds used as positive controls were, respectively, in the absence and presence of S-9: TA-98 (2-nitrofluorene and benzo[a]pyrene), TA100 (sodium azide and 2-aminoanthracene), TA1535 (sodium azide and 2-aminoanthracene), TA1537 (9-aminoacridine and 2-aminoanthracene), and TA102 (mitomycin C and 2-aminoanthracene). DEA was formulated in anhydrous dimethyl sulfoxide (DMSO) and assayed in triplicate repeats at concentrations from 5 to $5000 \mu \mathrm{g} /$ plate.

\subsection{Quantitative Liquid Chromatography (LC)-MS Method for the Analysis of DEA}

The samples were extracted after protein precipitation with acetonitrile and analyzed using a C18 column in a Shimadzu high performance liquid chromatography (HPLC) system with a gradient of $0.1 \%$ trifluoroacetic acid in acetonitrile, followed by analysis in a SCIEX API 5000 triple quadrupole mass spectrometer. AZA was used as an internal standard.

\subsection{Metabolism and Metabolic Profile of DEA in Rat, Dog, Monkey and Human Primary Hepatocytes}

The studies were conducted by Covance Laboratories Inc. in accordance with the company standard operating procedures. Cryopreserved hepatocytes from male Sprague Dawley rats, beagle dogs, cynomolgus monkeys, and pooled female human hepatocytes were obtained from BioIVT (Baltimore, MD, USA). Prior to performing the incubations, the viability of hepatocytes was evaluated by counting on a Cellometer (Nexcelom Biosciences, Lawrence, MA, USA). The assays were performed using $8 \times 10^{6}$ viable cells per $\mathrm{ml}$ of the incubation mixture. 
Chemical stability of DEA was determined by incubating 1 and $10 \mu \mathrm{M}$ DEA in serumfree Williams' Medium E for up to $120 \mathrm{~min}$, and measuring the remaining DEA concentrations. Metabolic activity of the hepatocytes under test article incubation conditions was measured using standard protocols [26,27] with minor modifications. DEA (1 and $10 \mu \mathrm{M})$ was incubated with rat, dog, monkey, and human hepatocytes for up to $120 \mathrm{~min}$. The remaining DEA concentrations were measured as described above.

\subsection{Metabolic Stability of DEA in Human Saliva}

Aliquots of human saliva (approximately 1 to $2 \mathrm{~mL}$ ) from two healthy subjects were freshly collected into $12 \mathrm{~mL}$ polypropylene test stock tubes and gently inverted 5 times to assure sample homogeneity. Aliquots of $100 \mu \mathrm{L}$ of the stock specimens were incubated in microcentrifuge tubes with $22 \mathrm{mM}$ DEA (final concentration) with gentle shaking on a horizontal plate shaker at room temperature. At select times of 120, 60, 30, 15, 5 and 0 min of incubation, $40 \mu \mathrm{L}$ aliquots of the incubates were mixed with an equal volume of the thin layer chromatography (TLC) mobile phase (hexane/acetone 70:30 v/v). AZA $(22 \mathrm{mM})$ in serial dilutions in the mobile phase was used as a control. TLC was performed as described [28] using $10 \times 10 \mathrm{~cm}$ silica gel plates with aluminum backing and fluorescent $\mathrm{UV}_{254}$ background (Whatman; Maidstone, UK) in a glass latch-lid ChromoTank with a 6-plate rack (General Glassblowing Company, Richmond, CA, USA) that was preequilibrated with the mobile phase solution. The plates were developed until the mobile phase reached about $80 \%$ height of the plates, then air dried and visualized under UV light. Retardation factor (Rf) values of at least three separate measurements were defined as the distance travelled by a given component divided by the distance travelled by the solvent front.

\subsection{Animal Study Ethics Statement}

The animal studies were conducted by Covance Laboratories Inc. at the Madison, WI, USA site in accordance with the company standard operating procedures and in compliance with the Animal Welfare Act Regulations (9 CFR 3). The facility is accredited by the Association for Assessment and Accreditation of Laboratory Animal Care (AAALAC) International; renewed 11 July 2016; which uses the National Research Council Guide for the Care and Use of Laboratory Animals (Guide) as its primary reference standard. The site also maintains the National Institutes of Health Office of Laboratory Animal Welfare (OLAW) Assurance Statement \#A3218-01; expiration 31 July 2023; which is also based on compliance with the Guide. Covance supports the 3Rs principles: to reduce the number of animals used per study, to refine the experimental procedures, and to use non-animal alternatives when scientifically feasible. Humane care is provided through programs of animal care and use based on the Guide for the Care and Use of Laboratory Animals, Public Health Service Policy and the Animal Welfare Act regulations (USA) and relevant regulations such as Home Office (UK) and AAALAC International. The protocol \#8380089 for the study "Determination of The Pharmacokinetics of DEA After an Oral Dose to Rats" was approved by the Covance's Institutional Animal Care and Use Committee.

\subsection{Determination of the Pharmacokinetics of DEA after an Oral Dose to Rats}

Male Sprague Dawley rats (Envigo RMS, Indianapolis, IN, USA), 9-weeks-old and weighing approximately $250 \mathrm{~g}$, were acclimated to study conditions for three days prior to dose administration. The animals were group housed up to three animals/cage/group in polycarbonate cages with hardwood chip bedding. Certified Rodent Diet \#2016C (Envigo RMS) was provided ad libitum. Fresh water ad libitum was provided daily. Environmental and psychological enrichment and various cage and food enrichment that did not require analysis were offered in accordance with the applicable protocols. Environmental controls for the animal room were set to maintain a temperature of 20 to $26^{\circ} \mathrm{C}$, a relative humidity of $50 \pm 20 \%$, and a 12-h light/12-h dark cycle. Animals were not randomized and selected for use in the test based on overall health and body weight. 
DEA was prepared in corn oil to final dose levels of $0.1,1.0$ and $10 \mathrm{mg} / \mathrm{kg}$ and administered via a gavage needle to three animals per group. Animals were weighed at the time of animal selection and on the day of dose administration. Blood (approximately $0.3 \mathrm{~mL}$ ) was collected via a jugular vein into tubes containing $\mathrm{K}_{2}$ EDTA from each animal pre-dose and at approximately $0.25,0.5,1,2,4,8,12$ and $24 \mathrm{~h}$ post-dose, stored in chilled racks, and processed by centrifugation to obtain plasma within $1 \mathrm{~h}$ of collection. Plasma was maintained on dry ice prior to storage at $-70^{\circ} \mathrm{C}$.

\subsection{Examination of Physicochemical Properties of DEA for Its Potential as a Drug}

The octanol/water value of a logarithm of partition coefficient (log P) for DEA and AZA was calculated as described [29]. DEA drug potential was evaluated using the "Lipinski Rule of Five" [30,31].

\section{Results}

\subsection{Toxicity and Mutagenicity}

Building upon our earlier findings that demonstrated lack of DEA mutagenicity using in silico and in vitro assays [6], we have further expanded the study to include a panel of Samonella strains commonly used in testing developmental drugs [32]. The concentrations of DEA spanned a broad range, corresponding to approximately $1000 \%$ of the intended oral dose. Since DEA has limited solubility in aqueous solutions, DMSO was chosen as the best solvent for the mutagenicity studies.

Following control treatments of all the test strains, the evidence of toxicity in the form of a diminished background bacterial lawn and/or a marked reduction in revertant numbers was observed at DEA $\geq 1600 \mu \mathrm{g} /$ plate in strain TA1537 in the absence of S-9, and at $5000 \mu \mathrm{g} /$ plate in strains TA1535 and TA102 in the absence of S-9, and in strains TA100 and TA1537 in the presence of S-9. Precipitation of DEA was observed on all test plates at $\geq 1600 \mu \mathrm{g} /$ plate. The controls validated the functionality of the bacterial strains.

Following DEA treatment of the test strains in the absence and presence of S-9, no notable increases in revertant numbers were observed, and none that were $\geq 1.5$-fold (in strain TA102), $\geq 2$-fold (in strains TA98 and TA100) or $\geq 3$-fold (in strains TA1535 and TA1537) compared to the vehicle (DMSO) control. Figure 1 shows the results for the two highest concentrations of DEA that are quantitatively representative of all doses of the ester. In contrast to the DEA treatment, the numbers of revertants in positive controls increased up to 40-fold (TA1535 in the absence of S-9) and over 2000-fold (TA102 in the presence of S-9). Since the standard errors of the measurements were all $<10 \%$, except for the positive control for TA102 without S-9 (16\% error), the error bars are not shown.

Overall, DEA was not mutagenic in the examined $S$. typhimurium strains at concentrations up to $1600 \mu \mathrm{g} /$ plate, both with and without the activation system S-9.

\subsection{Metabolism and Metabolic Profile of DEA In Vitro Using Rat, Dog, Monkey, and Human Hepatocytes}

The liver is the major site of metabolism of many drugs, and hepatocytes are commonly used to assess drug metabolism in preclinical studies. We have examined DEA metabolism in hepatocytes from representative animal models in a side-by-side comparison with human hepatocytes. In the past, we have shown that DEA was non-toxic up to concentrations as high as $25 \% v / v$ in different types of normal human cells [6]. In the present studies in mammalian hepatocytes, the concentrations of DEA corresponded to the anticipated liver levels of the ester following a single oral or an intravenous dose in vivo.

Further, we have selected $10 \mu \mathrm{M}$ of DEA as the highest concentration in hepatocyte tests based on our clinical dose of DEA of $1 \mathrm{mg} / \mathrm{kg}$ [24] corresponding to the maximum plasma level of $57 \mu \mathrm{M}$ DEA. This would be the maximum level of DEA in the absence of any metabolism. It was reasonable to expect that much lower levels of DEA in plasma would reach hepatocytes, thus $10 \mu \mathrm{M}$ DEA is likely to represent a high dose that may never be attained in vivo. 
We have noted in the past that the levels of AZA and its esters appear to be dynamically regulated immune responses, as illustrated by their increase in the response to toxin exposure [7].

First, we determined the chemical stability of DEA in Williams' Medium E. For $1 \mu \mathrm{M}$ DEA, the remaining levels of the ester were $82,76,42,48,41,38$, and $28 \%$ of the 0 -min control after incubation for 5, 15, 30, 45, 60, 90, and $120 \mathrm{~min}$, respectively. For $10 \mu \mathrm{M}$ DEA, the remaining levels were $98,81,63,49,38,33$ and $25 \%$ of the 0 -min control after incubation for $5,15,30,45,60,90$, and 120, respectively (Figure 2). These experiments indicated that DEA was chemically unstable, with approximately $25 \%$ remaining after $120 \mathrm{~min}$, corresponding to a mean value of half-life of $52 \mathrm{~min}$.

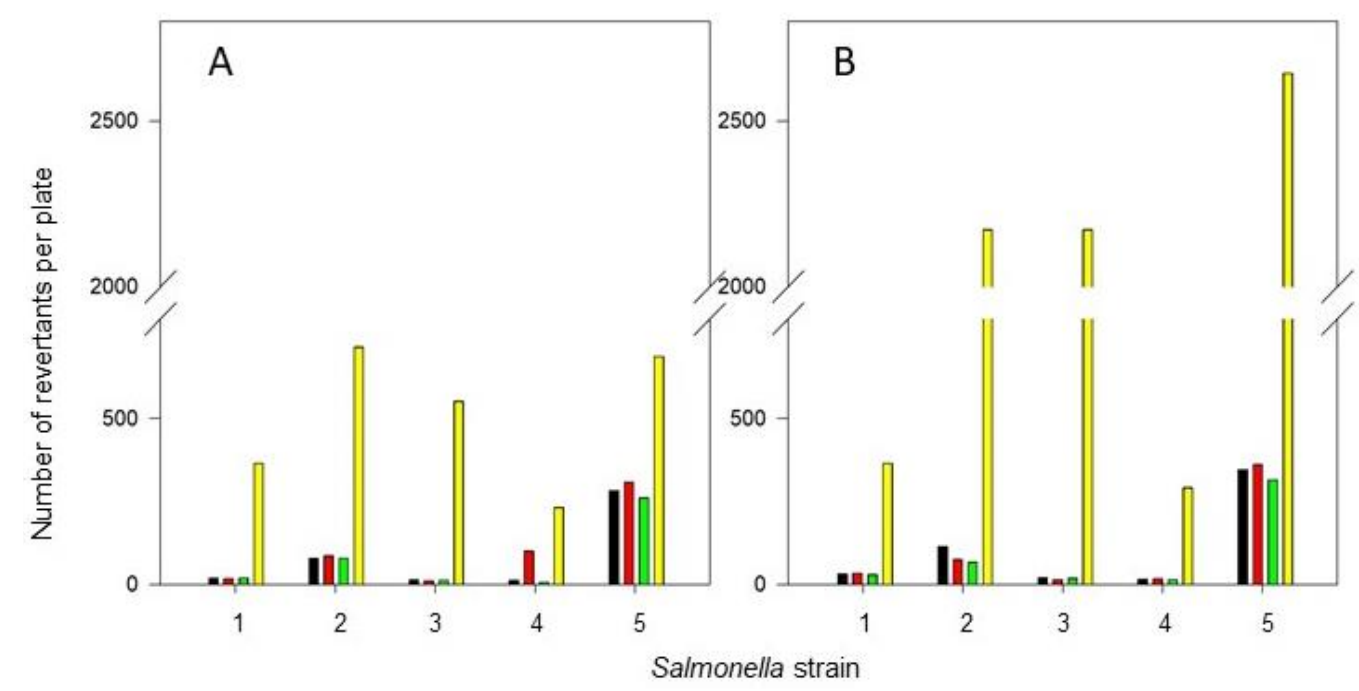

Figure 1. Mutagenicity tests of diethyl azelate (DEA) in Salmonella strains in the absence (A) and in the presence (B) of S-9 activation. On the $X$ axis, the consecutive numbers correspond to the Salmonella strains TA98, TA100, TA1535, TA1537, and TA102, respectively. The numbers on the $\mathrm{Y}$ axis indicate the numbers of revertants per plate. The treatment groups are: a negative control/DMSO solvent (black), DEA at $500 \mu \mathrm{g} /$ plate (red), DEA at $1600 \mu \mathrm{g} /$ plate (green), and positive controls for each Salmonella strain (yellow), as described under Materials and Methods.

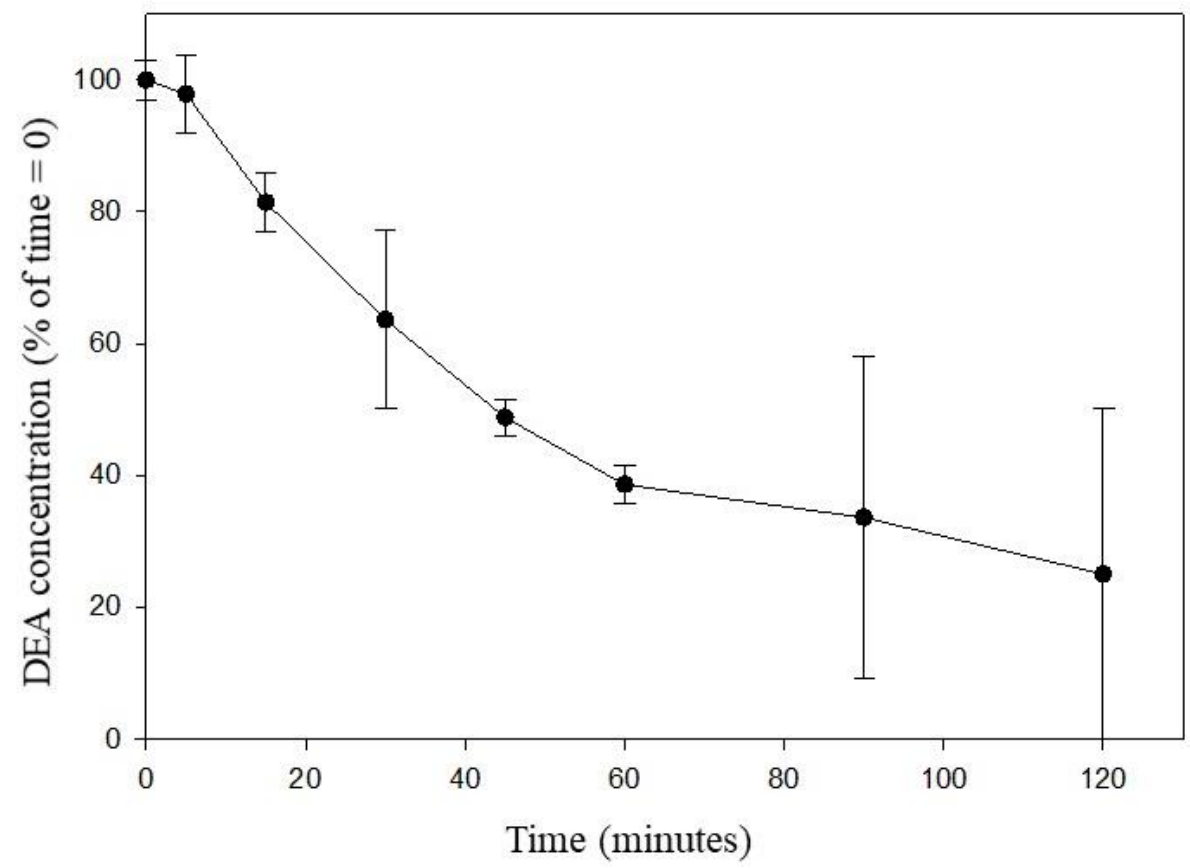

Figure 2. Chemical stability of DEA in cell culture medium; $10 \mathrm{mM}$ DEA was incubated in Williams's Medium E and the remaining levels (mean $\pm \mathrm{SD}$ ) were quantified at indicated time points using LC-MS, as described under Materials and Methods. 
Metabolic stability of DEA was determined by incubating 1 and $10 \mu \mathrm{M}$ DEA with the hepatocytes. In rat hepatocytes at $1 \mu \mathrm{M}$ DEA, the remaining DEA was below the detection limit of $0.025 \mu \mathrm{M}$ at all time points. With $10 \mu \mathrm{M}$ of DEA, the remaining DEA was only detected at 5,15 , and $30 \mathrm{~min}(0.08,0.07$, and $0.04 \mu \mathrm{M}$ corresponding to $0.55,0.47$, and $0.27 \%$ of 0 -min control, respectively) and was undetectable at the later time points. In dog hepatocytes dosed at 1 and $10 \mu \mathrm{M}$ of DEA, the remaining DEA was below the detection limits at all time points. In monkey hepatocytes dosed at $1 \mu \mathrm{M}$ DEA, the remaining DEA was below the detection limits at all times. In monkey hepatocytes dosed at $10 \mu \mathrm{M}$ DEA, the residual remaining DEA was detected only at $5 \mathrm{~min}(0.03 \mu \mathrm{M}$ corresponding to $0.2 \%$ of 0-min control). In human hepatocytes dosed at 1 and $10 \mu \mathrm{M}$ DEA, the remaining DEA was undetectable at all time points. An estimated half-life for DEA in rat hepatocytes was $0.6 \mathrm{~min}$ and in other cases the half-lives were even shorter. Overall, the results suggest a very high hepatic metabolism of DEA in rat, dog, monkey, and human hepatocytes.

\subsection{Determination of the Pharmacokinetics of DEA after an Oral Dose to Rats}

Although both plasma and whole blood are used in drug pharmacokinetic studies, plasma is the preferred matrix [33], and for this reason we have selected the latter.

After an oral gavage administration of DEA at all dose levels, neither diethyl or monoethyl azelate were detectable in the rat plasma (with the lower limit of quantitation at $<10.0 \mathrm{ng} / \mathrm{mL}$ ). As shown in Figure 3, AZA readily appeared in plasma with mean maximum time values ranging from 0.25 to $1.75 \mathrm{~h}$. After reaching the maximum concentrations, AZA levels declined with individual half-life values of 1.18 and $1.16 \mathrm{~h}$ at the 1 and $10 \mathrm{mg} / \mathrm{kg}$ dose levels, respectively. Due to the lack of a distinct elimination phase, estimation of elimination phase half-life was not attempted for most animals. The changes of the mean plasma levels of AZA over time (Figure 3) show that exposure to AZA generally increased with the increase in DEA dose level from 0.1 to $10 \mathrm{mg} / \mathrm{kg}$.

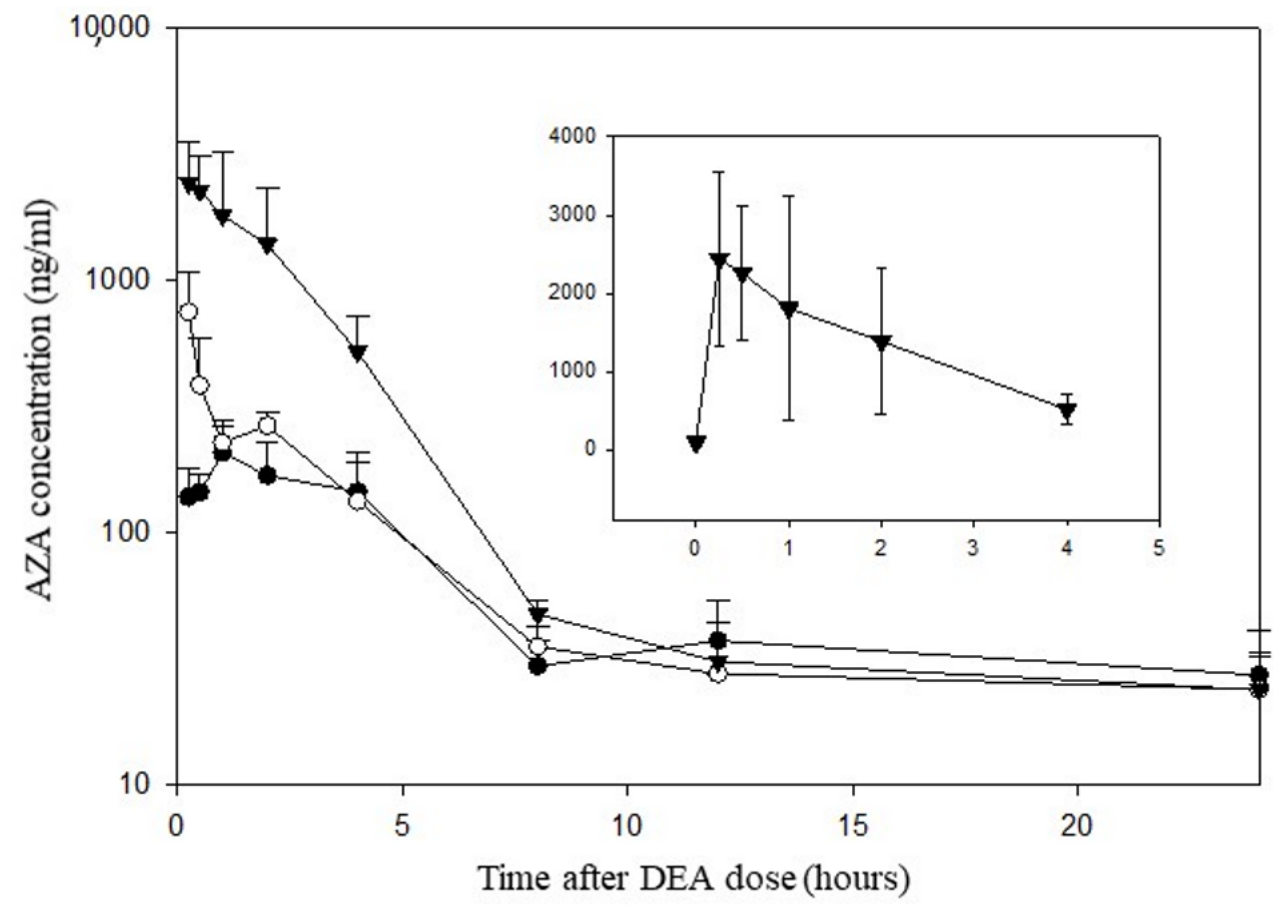

Figure 3. Levels of azelaic acid (AZA) in rat plasma following a single oral administration of DEA. Mean ( \pm SD) plasma levels of AZA in male rats dosed with DEA at $0.1 \mathrm{mg} / \mathrm{kg}$ (filled circles), $1 \mathrm{mg} / \mathrm{kg}$ (open circles), and $10 \mathrm{mg} / \mathrm{kg}$ (filled triangles) were quantified at indicated time points using LC-MS, as described under Materials and Methods. Inset: The plasma levels of AZA at $10 \mathrm{mg} / \mathrm{kg}$ DEA dose. The labels of the $\mathrm{x}$ and $\mathrm{y}$ axes are the same as in the full figure, the time frame is from 0 to $4 \mathrm{~h}$. 
The increases in AZA mean maximum concentrations and the values of areas under the curve from 0 to $24 \mathrm{~h}$ were less than dose proportional between the 0.1 to $10 \mathrm{mg} / \mathrm{kg}$ dose levels. When the higher dose levels of 1 and $10 \mathrm{mg} / \mathrm{kg}$ were compared, the corresponding values of areas under the curve from 0 to $24 \mathrm{~h}$ were proportional to the dose. In general, the levels of AZA increased with the increase in DEA doses from 0.1 to $10 \mathrm{mg} / \mathrm{kg}$.

\subsection{Metabolism of DEA in Human Saliva}

Since DEA is being contemplated for the use in oral applications in a liquid form, it was of interest to determine the stability of the ester in saliva, given that saliva contains multiple types of esterases known to display large inter-individual differences that are also diet-related [34,35].

We have used the DEA band with a Rf of 0.9 to monitor the earliest time when DEA was no longer detectable in saliva. This time varied between 5 and 60 min on different days of saliva sampling, and also differed between the two individuals. DEA was apparently hydrolyzed to AZA that moved with the solvent front on the TLC plates.

The variable rates for DEA hydrolysis by saliva could result from the differences in the activities of saliva esterases.

\subsection{Is DEA a "Druggable" Molecule}

According to one definition, a drug-like molecule has a $\log \mathrm{P}$ between -0.4 and 5.6, molecular weight 160-480 g/mol, and molar refractivity of 40-130, which is related to the volume and molecular weight of the molecule that has 20-70 atoms [30]. The calculated value of $\log P$ for DEA is 2.892. In comparison, the $\log P$ for azelaic acid is 1.136 [29].

Small molecules are more easily taken up by the cells, thus molecular weights below 500 Daltons are usually favorable for oral absorption [36]. With the molecular weight of DEA of $244.33 \mathrm{~g} / \mathrm{mol}$, it is anticipated to be absorbed in the gastrointestinal tract. Absorption after oral administration of DEA is also expected since all five rules of the "Lipinski Rule of Five" [30,31] are fulfilled. Most drugs on the market have molecular weights between 200 and 600 Daltons, and the molecules under 500 Daltons are considered to be small molecules. Thus, based on multiple criteria, DEA is a drug-like small molecule.

\section{Discussion}

We have shown that DEA has a favorable safety profile in various models relevant for the potential nutritional supplement or drug use of the molecule. The data showing lack of mutagenic activity of DEA in bacterial models are in agreement with our earlier studies in silico and in vitro that have demonstrated no genotoxicity of DEA and other azelates [6]. These results are consistent with the reports on nontoxic, nonteratogenic, and nonmutagenic properties of AZA [37], which is not only the metabolic precursor but also the metabolite of DEA. At the same time, it is not surprising to see bacterial toxicity of DEA in the light of known antibacterial activities of AZA [38] and some azelates [39].

The chemical stability tests suggest that DEA undergoes a relatively rapid hydrolysis in aqueous solution represented by the serum-free cell culture medium. To date we have evaluated the stability of DEA in cell culture medium and in rat plasma, both at physiologically relevant temperatures. In the future, once the developmental path of DEA has been decided (as a drug, nutraceutical, or both), we will perform the required stability studies of DEA in the formulation(s) selected for the commercial product to evaluate its shelf life. These studies will include testing the DEA product over a range of temperatures for several months.

It is expected that the rate of clearance of DEA in blood will be even more rapid due to the binding of DEA to serum proteins and hydrolysis by serum esterases [40].

Our studies have demonstrated rapid metabolism of DEA in vitro and in vivo. Since. DEA is rapidly converted to AZA upon oral administration, it is unlikely for DEA to reach hepatocytes. Notably, the metabolism of AZA in hepatocytes and potential downstream targets of AZA have been described elsewhere [41-43]. 
The degradation of DEA by mammalian hepatocytes and human saliva in vitro suggests that the ester has a very short physiological half-life and thus militates against the accumulation of high levels of DEA on repeated administration, as well as reducing the potential for drug-drug interactions.

The metabolic study in rats after an oral administration of DEA has demonstrated a rapid conversion of DEA to AZA, followed by a prompt elimination of AZA. Hydrolysis of DEA by saliva suggests that the earliest processing of orally taken DEA can happen in the mouth. The oral persistence of DEA may be affected by the intake of certain foods, in particular wine $[44,45]$.

Disregarding the route of administration, either as a liquid taken orally or as a swallowed capsule approximating the delivery by gavage in the animal study, the metabolism of DEA is expected to be rapid.

Our data are consistent with earlier observations of the half-lives of AZA in healthy human subjects of approximately $45 \mathrm{~min}$ after oral dosing and $12 \mathrm{~h}$ after topical dosing, indicating percutaneous absorption rate-limited kinetics [46]. The pharmacokinetics of AZA were evaluated in subjects who received an infusion of $10 \mathrm{~g}$ AZA or $1 \mathrm{~g}$ oral dose. However, due to extensive elimination through urinary excretion and a low cellular uptake, AZA was found unsuitable as an alternative energy substrate in total parenteral nutrition [47]. Our results are also in agreement with the report on the azelates, which are converted to AZA by esterases upon penetration into the tissues [39].

Looking at our findings in a broader context, we are reminded that the metabolism of DEA, like other esters of other fatty acids, occurs at first via enzymatic and/or chemical hydrolysis, leading to the formation of AZA and ethanol. In some cases, the hydrolysis of certain diesters may be incomplete and result in the formation of monoesters [48]. Increased levels of AZA monoesters have been reported in steatohepatitis and in response to dioxin exposure [49]. AZA can be further metabolized and its catabolites, mainly pimelic acid, are found in serum and urine, indicative of mitochondrial $\beta$-oxidation. AZA can also be conjugated to form more polar products that are excreted in urine [50,51].

Although DEA and AZA are metabolically related, we must keep in mind that DEA and related azelates have been shown to be entirely different pharmacological entities from AZA. Based on their distinct pharmacodynamics proteomic signatures, it is clear that DEA, as well as other azelates, cannot be viewed as mere precursors of AZA [6].

\subsection{The Levels of AZA and DEA in Human Body and in the Food}

Considerable quantities of fatty acid ethyl esters $\left(>300 \mathrm{pmol} / 10^{6}\right.$ cells) are synthesized endogenously in cultured human mononuclear cells upon exposure to dietary doses of ethanol [52].

The average level of AZA in human blood is $27.0 \mu \mathrm{M}$ (range from 0.0 to $58 \mu \mathrm{M}$ ) [53], $17 \pm 17 \mu \mathrm{M}$ in cerebrospinal fluid [53], and $0.0648 \pm 0.127 \mu \mathrm{M}$ in saliva [54]. The level of AZA in normal human breast milk is $101 \pm 72.5 \mu \mathrm{M}$ [55]. Thus, a $200 \mathrm{~mL}$ meal of mother's milk taken by a baby weighing $5 \mathrm{~kg}$ will deliver AZA at a dose of approximately $1 \mathrm{mg} / \mathrm{kg}$. This value is comparable with the daily oral dose of DEA in adult humans $(1 \mathrm{mg} / \mathrm{kg}$ or $0.1 \mathrm{~g}$ dose of DEA for an individual weighing $100 \mathrm{~kg}$ ) in a three-week clinical study whereby significant health benefits of lowering insulin resistance have been achieved without adverse side effects [17]. Incidentally, the lactation has been reported to correlate with a decrease in the incidence of Type 2 diabetes and circulating lipids in women [56,57].

Oleic acid, the endogenous precursor of AZA [1], is the most common monounsaturated fatty acid in nature. Oleic acid is the most abundant fatty acid in adipose tissue and second in abundance in human tissue overall, after palmitic acid [2]. It is present at high levels of up to $3.2 \mathrm{mM}$ in normal human plasma [58]. However, animal studies suggest that the endogenous synthesis of oleic acid does not compensate for nutritional deficiency $[59,60]$.

Although plant-derived food ingredients can vary widely in their composition [61], it is known that grains such as wheat, rye, and barley contain 0.4 to $7 \mathrm{mg}$ AZA per gram [62]. 
One ounce ( $28 \mathrm{~g}$ ) of these cereals can provide up to $0.2 \mathrm{~g}$ AZA [48]. Thus, a serving of $200 \mathrm{~g}$ breakfast cereal will provide approximately $1.4 \mathrm{~g}$ of AZA [48], well above the clinically effective molar dose of DEA [24].

If we assume a very unlikely scenario that the entire $100 \mathrm{mg}$ dose of oral DEA ends up in human blood and that the volume of the blood in body is $7 \mathrm{~L}$, the maximum concentration of DEA in blood will be $14 \mathrm{mg}$ per liter or $57 \mu \mathrm{M}$. This is comparable with the normal levels of AZA in human breast milk [55].

Olive oil contains approximately $70 \%$ oleic acid and considerable quantities of fatty acid ethyl esters [63]. Azelate levels vary widely in fermented foods and liquors. The reported levels of DEA per liter of fermented soybean and rice-flavored liquors range from $9 \mu \mathrm{g}$ [14] to $86.6 \mu \mathrm{g}$ [15].

\subsection{Oral Safety of AZA and Related Azelates}

The no-observed-adverse-effect-level (NOAE) values were $100 \mathrm{mg} / \mathrm{kg}$ body weight/day given to rodents for 27 weeks and $800 \mathrm{mg} / \mathrm{kg} /$ day given to dogs for 6 months. No treatment-related effects were seen at $250 \mathrm{mg} / \mathrm{kg} /$ day administered to monkeys for 4 weeks [37]. Thus, AZA is not expected to cause detrimental health effects following repeated oral exposure.

Diethylhexyl azelate is approved for food contact packaging in the United States. DEA is approved as a flavoring additive in the European Union [64]. A closely related ester, diethyl sebacate, which differs from DEA by one methylene unit (as AZA is a C9 and sebacic acid is a C10 acid) is on the list of Generally Regarded As Safe (GRAS) compounds and on the Inactive Ingredients List of the US FDA [48].

\section{Conclusions}

Based on the published data, the main source of dietary AZA and azelates are cereals, followed by soy sauce and olive oil, and finally alcoholic beverages. Interestingly, mother's milk can deliver clinically relevant doses of AZA to infants.

The future applications of DEA either as a nutritional supplement or a drug will be used at daily doses similar to those used in the human study. Such doses are expected to be safe as they are well within the normal levels of dietary azelates.

Author Contributions: E.I. and R.T.S. conceptualized and performed the experiments, designed and supervised the contractual work done outside New Frontier Labs, analyzed the data and wrote the manuscript. All authors have read and agreed to the published version of the manuscript.

Funding: All research presented in the manuscript was funded by New Frontier Labs, LLC.

Institutional Review Board Statement: The study was conducted according to the guidelines of the Declaration of Helsinki, and approved by the Institutional Review Board at New Frontier Labs LLC, protocol code NF-001-018 approved on 2 February 2018.

Informed Consent Statement: Informed consent was obtained from both subjects involved in the study.

Data Availability Statement: Not applicable.

Conflicts of Interest: E.I. and R.T.S. are the owners and officers of New Frontier Labs, LLC.

\section{References}

1. Piccinin, E.; Cariello, M.; De Santis, S.; Ducheix, S.; Sabba, C.; Ntambi, J.M.; Moschetta, A. Role of oleic acid in the gut-liver axis: From diet to the regulation of its synthesis via stearoyl-CoA desaturase 1 (SCD1). Nutrients 2019, 11, 2283. [CrossRef] [PubMed]

2. Everts, S. Vegetative warfare. Chem. Eng. News 2011, 89, 53-55. [CrossRef]

3. Jung, H.W.; Tschaplinski, T.J.; Wang, L.; Glazebrook, J.; Greenberg, J.T. Priming in systemic plant immunity. Science 2009, 324, 89-91. [CrossRef] [PubMed]

4. Mastrofrancesco, A.; Ottaviani, M.; Aspite, N.; Cardinali, G.; Izzo, E.; Graupe, K.; Zouboulis, C.C.; Camera, E.; Picardo, M. Azelaic acid modulates the inflammatory response in normal human keratinocytes through PPAR gamma activation. Exp. Dermatol. 2010, 19, 813-820. [CrossRef] [PubMed]

5. Dorschner, R.A.; Williams, M.R.; Gallo, R.L. Rosacea, the face of innate immunity. Br. J. Dermatol. 2014, 171, 1282-1284. [CrossRef] 
6. Izbicka, E.; Streeper, R.; Louden, C. Adaptive membrane fluidity modulation: A feedback regulated homeostatic system and target for pharmacological intervention. In Vivo 2021, 35, 3073-3095. [CrossRef] [PubMed]

7. Izbicka, E.; Streeper, R. Adaptive membrane fluidity modulation: A feedback regulated homeostatic system hiding in plain sight. In Vivo 2021, 35, 2991-3000. [CrossRef] [PubMed]

8. Saerens, S.M.; Delvaux, F.; Verstrepen, K.J.; Van Dijck, P.; Thevelein, J.M.; Delvaux, F.R. Parameters affecting ethyl ester produc-tion by Saccharomyces cerevisiae during fermentation. Appl. Environ. Microbiol. 2008, 74, 454-461. [CrossRef] [PubMed]

9. Kostelenos, G.; Kiritsakis, A. Olive Tree History and Evolution. In Olives and Olive Oil as Functional Foods; Kiritsakis, A., Shahidi, F., Eds.; John Wiley \& Sons Ltd.: Oxford, UK, 2017; pp. 1-12.

10. Rahmani, M. Food hazards and quality control in table olive processing with a special reference to functional compounds. In Olives and Olive Oil as Functional Foods; Kiritsakis, A., Shahidi, F., Eds.; John Wiley \& Sons Ltd.: Oxford, UK, 2017 ; pp. 347-352.

11. Yamabe, S.; Kaneko, K.; Inoue, H.; Takita, T. Maturation of fermented rice-koji miso can be monitored by an increase in fatty acid ethyl ester. Biosci. Biotechnol. Biochem. 2004, 68, 250-252. [CrossRef]

12. Kim, J.; Chung, H. Components in commercial douchi a Chinese fermented black bean product by supercritical fluid ex-traction. J. Food Sci. Nutr. 2008, 13, 12-17.

13. Yu, J. Determination of Binary Acids Diethyl Esters in Fermented Soya Beans-Flavour Liquor by Gas Chromatography. 2001. Available online: http:/ / en.cnki.com.cn/Article_en/CJFDTOTAL-NJKJ200106033.htm (accessed on 10 May 2019).

14. Du, J.; Li, Y.; Xu, J.; Huang, M.; Wang, J.; Chao, J.; Wu, J.; Sun, H.; Ding, H.; Ye, H. Characterization of key odorants in langyatai baijiu with jian flavour by sensory-directed analysis. Food Chem. 2021, 352, 129363. [CrossRef]

15. Fan, H.; Fan, W. Characterization of key odorants in Chinese chixiang aroma-type liquor by gas chromatographyolfactometry, quantitative measurements, aroma recombination, and omission studies. J. Agric. Food Chem. 2015, 63, 3660-3668. [CrossRef] [PubMed]

16. Nazzaro-Porro, M. Azelaic acid. J. Am. Acad. Dermatol. 1987, 17, 1033-1041. [CrossRef]

17. Nazzaro-Porro, M.; Passi, S.; Zina, G.; Bernengo, A.; Breathnach, A.; Gallagher, S. Effect of azelaic acid on human malignant melanoma. Lancet 1980, 1, 1109-1111. [CrossRef]

18. Breathnach, A.; Levi-Montalcini, R. The story of azelaic acid. A tribute to Marcella Nazzaro-Porro. Rend. Fis. Acc. Lincei 1995, 6, 313-320. [CrossRef]

19. Searle, T.; Ali, F.R.; Al-Niaimi, F. The versatility of azelaic acid in dermatology. J. Dermatol. Treat. 2020. [CrossRef] [PubMed]

20. Wang, Z.; Xiang, H.; Dong, P.; Zhang, T.; Lu, C.; Jin, T. Pegylated azelaic acid: Synthesis, tyrosinase inhibitory activity, antibacterial activity and cytotoxic studies. J. Mol. Struct. 2021, 1234, 129234. [CrossRef]

21. Streeper, R.T.; Izbicka, E. Azelaic Acid Esters in the Treatment of Insulin Resistance. U.S. Patent US 10,251,857 B2, 9 April 2019.

22. Streeper, R.T.; Izbicka, E. Azelaic Acid Esters in the Treatment of Insulin Resistance. U.S. Patent US 11,026,912 B2, 8 June 2021.

23. Streeper, R.T.; Izbicka, E. Azelaic Acid Esters in the Treatment of Dyslipidemia and Associated Conditions. U.S. Patent Application US/2021/0251939 A1, 19 August 2021.

24. Streeper, R.T.; Louden, C.; Izbicka, E. Oral azelaic acid ester decreases markers of insulin resistance in overweight human male subjects. In Vivo 2020, 34, 1173-1186. [CrossRef]

25. Maron, D.M.; Ames, B.N. Revised methods for the Salmonella mutagenicity test. Mutat. Res. 1983, 113, 173-215. [CrossRef]

26. Bayliss, M.K.; Bell, J.A.; Jenner, W.N.; Park, G.R.; Wilson, K. Utility of hepatocytes to model species differences in the metabo-lism of loxtidine and to predict pharmacokinetic parameters in rat, dog and man. Xenobiotica 1999, 29, 253-268. [CrossRef]

27. Tee, L.B.; Seddon, T.; Boobis, A.R.; Davies, D.S. Drug metabolising activity of freshly isolated human hepatocytes. Br. J. Clin. Pharmacol. 1985, 19, 279-294. [CrossRef] [PubMed]

28. Esperon-Rojas, A.A.; Torres-Palacios, C.; Santos-Luna, D.; Baeza-Jimenez, R.; Cano-Sarmiento, C.; Garcia, H.S. A specific thin layer chromatography method for the identification and separation of medium chain acylglycerols. J. Oleo Sci. 2018, 67, 1397-1403. [CrossRef] [PubMed]

29. Moriguchi, I.; Hirono, S.; Liu, Q.; Nakagome, I.; Matsushita, Y. Simple method of calculating octanol/water partition coefficient. Chem. Pharm. Bull. 1992, 40,127-130. [CrossRef]

30. Ghose, A.K.; Viswanadhan, V.N.; Wendoloski, J.J. A knowledge-based approach in designing combinatorial or medicinal chemistry libraries for drug discovery. A qualitative and quantitative characterization of known drug databases. J. Comb. Chem. 1999, 1, 55-68. [CrossRef]

31. Lipinski, C.A.; Lombardo, F.; Dominy, B.W.; Feeney, P.J. Experimental and computational approaches to estimate solubility and permeability in drug discovery and development settings. Adv. Drug Deliv. Rev. 2001, 46, 3-26. [CrossRef]

32. Escobar, P.A.; Kemper, R.A.; Tarca, J.; Nicolette, J.; Kenyon, M.; Glowienke, S. Bacterial mutagenicity screening in the pharmaceutical industry. Mutat. Res. 2013, 752, 99-118. [CrossRef]

33. Dash, R.; Veeravalli, V.; Thomas, J.; Rosenfeld, C.; Mehta, N.; Srinivas, N. Whole blood or plasma: What is the ideal matrix for pharmacokinetic-driven drug candidate selection? Future Med. Chem. 2020, 13, 157-171. [CrossRef]

34. Lindqvist, L.; Augustinsson, K. Esterases in human saliva. Enzyme 1975, 20, 277-291. [CrossRef] [PubMed]

35. Perez-Jimenez, M.; Munoz-Gonzales, C.; Pozo-Bayon, M.A. Understanding human salivary esterases activity and its varia-tion under wine consumption conditions. R. Soc. Chem. 2020, 10, 24352-24361. [CrossRef] 
36. Veber, D.F.; Johnson, S.R.; Cheng, H.Y.; Smith, B.R.; Ward, K.W.; Kopple, K.D. Molecular properties that influence the oral bioa-vailability of drug candidates. J. Med. Chem. 2002, 45, 2615-2623. [CrossRef]

37. Australian Government Department of Health. Nonanedioic acid (Azelaic Acid). Evaluation Statement. 2021. Available online: https:/ / www.industrialchemicals.gov.au/sites/default/files/2021-09/EVA00010\%20-\%20Evaluation\%20Statement\% 20-2014\%20September\%202021\%20\%5B702\%20KB\%5D.pdf (accessed on 20 September 2021).

38. Leeming, J.P.; Holland, K.T.; Bojar, R.A. The in vitro antimicrobial effect of azelaic acid. Br. J. Derm. 1986, 115, 551-556. [CrossRef]

39. Charnock, C.; Brudeli, B.; Klaveness, J. Evaluation of the antibacterial efficacy of diesters of azelaic acid. Eur. J. Pharm. Sci. 2004, 21, 589-596. [CrossRef]

40. Goncharov, N.V.; Belinskaia, D.A.; Shmurak, V.I.; Terpilowski, M.A.; Jenkins, R.O.; Avdonin, P.V. Serum albumin binding and esterase activity: Mechanistic interactions with organophosphates. Molecules 2017, 22, 1201. [CrossRef]

41. Muthulakshmi, S.; Saravanan, R. Efficacy of azelaic acid on hepatic key enzymes of carbohydrate metabolism in high fat diet induced type 2 diabetic mice. Biochimie 2013, 95, 1239-1244. [CrossRef]

42. Thach, T.T.; Hong, Y.J.; Lee, S.; Lee, S.J. Molecular determinants of the olfactory receptor Olfr544 activation by azelaic acid. Biochem. Biophys. Res. Commun. 2017, 485, 241-248. [CrossRef]

43. Thach, T.T.; Wu, C.; Hwang, K.Y.; Lee, S.J. Azelaic Acid Induces Mitochondrial Biogenesis in Skeletal Muscle by Activation of Olfactory Receptor 544. Front. Physiol. 2020, 11, 329. [CrossRef]

44. Munoz-Gonzalez, C.; Perez-Jimenez, M.; Pozo-Bayon, M.A. Oral persistence of esters is affected by wine matrix composition. Food Res. Int. 2020, 135, 109286. [CrossRef]

45. Perez-Jimenez, M.; Esteban-Fernandez, A.; Munoz-Gonzalez, C.; Pozo-Bayon, M.A. Interactions among odorants, phenolic compounds, and oral components and their effects on wine aroma volatility. Molecules 2020, 25, 1701. [CrossRef]

46. Passi, S.P.M.; De Luca, C.; Nazzaro-Porro, M. Mechanism of azelaic acid action in acne. G. Ital. Derm. Venereol. 1989, 124, 455-463.

47. Bertuzzi, A.; Gandolfi, A.; Salinari, S.; Mingrone, G.; Arcieri-Mastromattei, E.; Finotti, E.; Greco, A.V. Pharmacokinetic analysis of azelaic acid disodium salt. A proposed substrate for total parenteral nutrition. Clin. Pharm. 1991, 20, 411-419. [CrossRef]

48. Fiume, M.M.; Eldreth, H.B.; Bergfeld, W.F.; Belsito, D.V.; Hill, R.A.; Klaassen, C.D.; Liebler, D.; Marks, J.G.; Shank, R.C.; Slaga, T.J.; et al. Final Report of the Cosmetic Ingredient Review Expert Panel on the Safety Assessment of Dicarboxylic Acids, Salts, and Esters. Int. J. Toxicol. 2012, 31 (Suppl. SI), 5S-76S. [CrossRef] [PubMed]

49. Matsubara, T.; Tanaka, N.; Krausz, K.W.; Manna, S.K.; Kang, D.W.; Anderson, E.R. Metabolomics identifies an inflammatory cascade involved in dioxin- and diet-induced steatohepatitis. Cell Metab. 2012, 16, 634-644. [CrossRef]

50. Grego, A.V.; Mingrone, G. Dicarboxylic acids, an alternate fuel substrate in parenteral nutrition: An update. Clin. Nutr. 1995, 14, 143-148. [CrossRef]

51. Passi, S.; Picardo, M.; Mingrone, G.; Breathnach, A.S.; Nazzaro-Porro, M. Azelaic acid-biochemistry and metabolism. Acta Derm. Venereol. 1989, 143, 8-13. [CrossRef]

52. Alhomsi, K.; Cluette-Brown, J.E.; Laposata, M. Fatty acid ethyl esters in human mononuclear cells: Production by endogenous synthesis greatly exceeds the uptake of preformed ethyl esters. Alcohol. Clin. Exp. Res. 2006, 30, 560-566. [CrossRef] [PubMed]

53. Hoffmann, G.F.; Meier-Augenstein, W.; Stockler, S.; Surtees, R.; Rating, D.; Nyhan, W.L. Physiology and pathophysiology of organic acids in cerebrospinal fluid. J. Inherit. Metab. Dis. 1993, 16, 648-669. [CrossRef]

54. Sugimoto, M.; Saruta, J.; Matsuki, C.; To, M.; Onuma, H.; Kaneko, M.; Soga, T.; Tomita, M.; Tsukinoki, K. Physiological and environmental parameters associated with mass spectrometry-based salivary metabolomic profiles. Metabolomics 2013, 9 , 454-463. [CrossRef]

55. Smilowitz, J.T.; O'Sullivan, A.; Barile, D.; German, J.B.; Lonnerdal, B.; Slupsky, C.M. The human milk metabolome reveals diverse oligosaccharide profiles. J. Nutr. 2013, 143, 1709-1718. [CrossRef]

56. Gunderson, E.P.; Hurston, S.R.; Ning, X.; Lo, J.C.; Crites, Y.; Walton, D.; Dewey, K.G.; Azevedo, R.A.; Young, S.; Fox, G.; et al. Study of Women IF and Type 2 Diabetes After GDMPI: Lactation and progression to type 2 diabetes mellitus after gestational diabetes mellitus: A prospective cohort study. Ann. Intern. Med. 2015, 163, 889-898. [CrossRef]

57. Zhang, Z.; Lai, M.; Piro, A.L.; Alexeeff, S.E.; Allalou, A.; Rost, H.L.; Dai, F.F.; Wheeler, M.B.; Gunderson, E.P. Intensive lactation among women with recent gestational diabetes significantly alters the early postpartum circulating lipid profile: The swift study. BMC Med. 2021, 19, 241. [CrossRef]

58. Abdelmagid, S.A.; Clarke, S.E.; Nielsen, D.E.; Badawi, A.; El-Sohemy, A.; Mutch, D.M.; Ma, D.W. Comprehensive profiling of plasma fatty acid concentrations in young healthy Canadian adults. PLoS ONE 2015, 10, e0116195. [CrossRef]

59. Bourre, J.M.; Dumont, O.L.; Clement, M.E.; Durand, G.A. Endogenous synthesis cannot compensate for absence of dietary oleic acid in rats. J. Nutr. 1997, 127, 488-493. [CrossRef] [PubMed]

60. Bourre, J.M.; Dumont, O.; Durand, G. Dose-effect of dietary oleic acid: Oleic acid is conditionally essential for some organs. Reprod. Nutr. Dev. 2004, 44, 371-380. [CrossRef]

61. Catlin, N.R.; Collins, B.J.; Auerbach, S.S.; Ferguson, S.S.; Harnly, J.M.; Gennings, C.; Waidyanatha, S.; Rice, G.E.; Smith-Roe, S.L.; Witt, K.L.; et al. How similar is similar enough? A sufficient similarity case study with ginkgo biloba extract. Food Chem. Toxicol. 2018, 118, 328-339. [CrossRef] [PubMed] 
62. Center for Drug Evaluation and Research. Application Number 21-470; Finacea Approval. Clinical Pharmacology and BioPharmaceutics Review(s). Available online: https://www.accessdata.fda.gov/drugsatfda_docs/nda/2002/21-470_Finacea_ Approv.pdf (accessed on 8 July 2021).

63. Palagano, R.; Valli, E.; Tura, M.; Cevoli, C.; Perez-Camino, M.D.C.; Moreda, W.; Bendini, A.; Toschi, T. Fatty acid ethyl esters in virgin olive oils: In-house validation of a revised method. Foods 2020, 9, 924. [CrossRef]

64. Regulation European Commission. Opinion of the scientific panel on food additives, flavourings, processing aids and mate-rials in contact with food (AFC) on a request from the commission related to flavouring group evaluation 10: Aliphatic pri-mary and secondary saturated and unsaturated alcohols, aldehydes, acetals, carboxylic acids and esters containing an addi-tional oxygenated functional group and lactones from chemical groups 9, 13 and 30 (commission regulation (EC) no 1565/2000 of 18 July 2000). EFSA J. 2005, 246, 1-110. 